DOI: https://doi.org/10.24297/jssr.v14i0.8042

\title{
Individual Profiles of Psychological Capital in a Spanish Sample
}

\author{
Nia Plamenova Djourova, Isabel Rodríguez, Laura Lorente-Prieto \\ Universitat de Valencia, Spain
}

nia.djourova@gmail.com, isabel.rodriguez@uv.es, laura.lorente-prieto@uv.es

\begin{abstract}
Psychological Capital (PsyCap) consists of hope, self-efficacy, resilience and optimism. It is usually assumed that individuals score similarly across these four components, however, there have been suggestions in the literature that in some cases, people can score high on some dimensions and low on others, and that it is necessary to explore the matter further (Dawkins, 2014). Hence, the main objective of this article is to explore if the relationship between the dimensions of PsyCap results in individual profiles; to see which sociodemographic characteristics they have, and how the profiles relate to job satisfaction and performance.

The sample consists of 1752 employees from different companies in Spain. We used Latent Profile Analysis and the results revealed that a four-profile model is the best fit for our data, where Profile 1 was characterized by low self-efficacy and hope, and high resilience and optimism; Profile 2 by high self-efficacy and hope, and low resilience and optimism; Profile 3 by low self-efficacy and high hope, resilience and optimism; and Profile 4 by high scores on all PsyCap constructs.

The majority of the sample was classified in Profile 4, showing support for the unitary structure of PsyCap. However, for some individuals scores differed across the four PsyCap dimensions. Furthermore, there were highlow and low-high configurations for hope and self-efficacy on the one hand, and resilience and optimism on the other. Lastly, our results emphasize the combination of hope and self-efficacy as important contributors to employee outcomes.
\end{abstract}

Keywords: profiles, psychological capital, hope, self-efficacy, resilience, optimism

\section{Introduction}

Psychological Capital (PsyCap) is currently a widely researched construct which originated from Positive Psychology and Positive Organizational Behavior: the application of positive personal capacities in the workplace (Avey, Reichard, Luthans, \& Mhatre, 2011; Imam, Ali, \& Soo, 2017; Luthans \& Youssef-Morgan, 2017; Newman, Ucbasaran, Zhu, \& Hirst, 2014). PsyCap is a second-order construct, which consists of four sub-dimensions: 1) self-efficacy: having confidence to take on and put in the necessary effort to succeed at challenging tasks; 2 ) hope: persevering toward goals and, when necessary, redirecting paths to goals in order to succeed; 3) resilience: when beset by problems and adversity, sustaining and bouncing back and even beyond to attain success; and 4) optimism: making a positive attribution about succeeding now and in the future (Luthans et al., 2007, p. 3).

The four PsyCap dimensions share many characteristics and PsyCap represents the underlying connection between them. PsyCap is defined as "one's positive appraisal of circumstances and probability for success based on motivated effort and perseverance" (Luthans, Avolio, Avey, \& Norman, 2007. p.10). Although the PsyCap dimensions are inter-correlated, they are independent, distinct variables which have been empirically shown to have discriminant validity (see Luthans, Avolio, \& Avey, 2007; Luthans \& Youssef-Morgan, 2007). In this sense, the four can be sufficiently independent, so that people can have different levels of hope, self-efficacy, resilience and optimism even though they are considered indicators of the same multidimensional construct. 
One of the main contributions of the PsyCap construct, which has been underlined by the authorship team is that as a multidimensional construct, PsyCap explains variance in outcome variables beyond the four dimensions that constitute it. However, this has not always been the case and in some instances the predictive power of PsyCap varies across samples (Luthans \& Youssef-Morgan, 2017).

In relation to this, (Dawkins, Martin, Scott, \& Sanderson, 2013) advocated the use of the four components separately to increase the understanding of how they work and relate to one another. Furthermore, Dawkins et al., (2013) stress the limitations of using a composite PsyCap score because it omits any information about the variance across the four dimensions, and points out the necessity "to further validate the use of a composite PCQ score" (p. 16). Her work lays emphasis on the possibility that the PsyCap components do not go in synchrony in all cases, and it is possible for some people to score high on some elements but low on others.

One way to address these concerns is through exploring whether individual PsyCap profiles exist, meaning profiles of individuals who score high on certain PsyCap dimensions but low on others. The most recent review on PsyCap by Luthans \& Youssef-Morgan, (2017) also recommends for future research should explore the "individuals who may be particularly low on one or more subcomponents and high on others" (p. 14).

It is also likely that certain profiles are linked to demographic variables, such as tenure (Dawkins, 2014). This is because some of the PsyCap dimensions, like self-efficacy, are built through previous experience, so it is likely that a more tenured employee will feel more highly efficacious in their job than a less experienced one. In this vein, it is useful to consider if people with certain demographics are more likely to have a certain PsyCap profile/typology. In addition, the value of testing for PsyCap profiles that differ across the four dimensions stems from the possibility that these profiles relate differently to employee outcomes (Dawkins, 2014). However, to our knowledge, none has explored this issue.

In line with all of the above, the first and primary objective of this article is to test whether individual profiles across the four PsyCap dimensions exist. Secondly, we explore how such profiles are related to demographics, particularly, gender, age, educational level, tenure and seniority. Thirdly, we relate these profiles to outcome variables of performance and satisfaction, specifically intrinsic satisfaction, in-role performance and OCB, as they are variables known to be influenced by PsyCap and its dimensions, but have not been tested previously in relation to specific PsyCap variation.

\section{Theoretical Background}

Multidimensional or superordinate constructs englobe a combination of specific dimensions (see Edwards, 2001 for a review), as is the case of PsyCap. They are defined by their dimensions; in other words, the dimensions are variables that function as specific indicators of a more general underlying construct (Edwards, 2001). Secondorder constructs are often used in research on personality and personal capacities, for example, core-selfevaluation (Judge \& Bono, 2001) or transformational leadership (Bass, 1999).

The utility of such multidimensional constructs is a subject of debate in the organizational behavior literature (Edwards, 2001). The defenders of multidimensional constructs have argued that they are more useful from a theoretical standpoint because they allow the generalization of theories and connect comprehensive concepts to broad outcomes, which is more realistic, practical and likely to explain more variance than separate components alone. This argument has been put forwards by the authoring team of PsyCap who have shown in some studies that the composite variable PsyCap predicts variance above and beyond its four components (Luthans, Avolio, \& Avey, 2007; Luthans \& Youssef-Morgan, 2017).

On the other hand, a number of authors have criticized the utility of multidimensional constructs due to ambiguity and lack of precision. They argue that the relationships between the sub-dimensions and outcome variables remain unclear and that any variation within the overall construct could mean variation within one or more of the sub-dimensions that is not tapped. Relationships between multidimensional constructs and other variables are very difficult to develop with theoretical accuracy since different explanations for the relationship 
can be given for different sub-dimensions of the construct (Johns, 1998). In addition, the multidimensional construct may explain less variance in outcomes than the sub-dimensions taken collectively.

This perspective can also be applied to PsyCap, as there are studies that concluded that the overall PsyCap factor does not predict wellbeing and performance beyond the four dimensions, thus questioning the use a second order factor and a composite score. For instance, (Kauko-Valli \& Haapanen, 2013) found that out of the four dimensions of PsyCap, only hope was positively related to the growth intentions of entrepreneurs. Rego, Marques, Leal, Sousa, \& Pina e Cunha, (2010) used the four dimensions separately, as well as the composite PsyCap score in a regressions analysis to predict performance in Portuguese civil servants. They even split the hope dimension into its components waypower and willpower (Snyder, 2015) and found out that most variance in performance was explained when the separate dimensions were introduced to the regression after the overall PsyCap factor (Rego et al., 2010). If the order was reversed, no additional variance was explained by the PsyCap factor. In addition, in their analysis, optimism, resilience and the willpower dimension of hope were significant predictors of performance, while self-efficacy and the waypower dimension were not.

Further questions regarding the multidimensional nature of PsyCap are raised by the use of its composite score. Superordinate constructs are often measured with subscales for each dimension and the composite score on their dimensions is what is utilized in statistical analysis. Although common, this approach is problematic because it does not tackle measurement error and ignores the unique contribution of each of the subdimensions, as well as the variance in each dimension which is not captured by the second-order factor (Bagozzi \& Edwards, 1998). Using a composite score has been pointed out as a limitation of the PsyCap measure, as it fails to account for variations across self-efficacy, hope, resilience and optimism (Dawkins, 2014; Dawkins, Martin, Scott, \& Sanderson, 2015).

Such variation is likely to exist because even though the four PsyCap dimensions share many characteristics, they are still separate constructs which are distinguished from one another. In terms of communalities, for example, hope and self-efficacy share a component of agency- the motivation and energy to pursue a goal (Luthans \& Jensen, 2002b); resilience and self-efficacy share a characteristic of perseverance in the face of difficulties (Luthans, Vogelgesang, \& Lester, 2006); optimism and hope share positive future expectancies (Luthans \& Jensen, 2002b), and optimism and resilience share emotional components of positivity, flexibility and adjustment (Fredrickson, Tugade, Waugh, \& Larkin, 2003; Peterson, 2000).

However, the PsyCap dimensions also differ in some ways and are generally considered to be independent constructs with discriminant validity (Carifio \& Rhodes, 2002; Luthans, Avolio, Avey, et al., 2007; Luthans \& Youssef-Morgan, 2007; Magaletta \& Oliver, 1999). For instance, hope and optimism differ in the degree of generalizability of positive expectancies (Luthans \& Jensen, 2002a). Self-efficacy and resilience differ in the type of perseverance that defines them: self-efficacy refers to maintaining motivation in the face of difficulties, while resilience refers to recuperating after difficulties have occurred (Luthans, Avolio, \& Avey, 2007; Magaletta \& Oliver, 1999). Thus, given that the PsyCap dimensions are unique and encompass different elements, they could be independent enough so that the same individual can have high levels of one or two dimensions, but low levels of the rest (Dawkins, 2014).

Dawkins (2014) gives an example of the issue: two employees could obtain the exact same total PsyCap score, however one could have scored high on self-efficacy and hope, and lower on optimism and resilience, while the other could have scored similarly across all four dimensions. In this case, using a composite PsyCap score would only inform of the overall level of the four dimensions, but it does not account for different PsyCap profiles (Dawkins, 2014; Luthans \& Youssef-Morgan, 2017). Dawkins (2014) further points out that it is important to determine if particular configurations or patterns emerge within the PsyCap dimensions and if there are individual typologies of PsyCap (Dawkins, 2014).

Such typologies may depend on variables like tenure, for instance, as is illustrated by Dawkins (2014): inexperienced employees on a new job are likely to exhibit more optimism and hope because they are starting something new, but less resilience and self-efficacy since those are built through past experiences of successfully 
dealing with specific work situations. A seasoned employee who has overcome work challenges in their previous experience is likely to have resilience and self-efficacy but may be lower on optimism and hope due to the predictability of the job they have been doing for a while (Dawkins,2014).

To extend this line of though, demographics such as age, gender or educational level can also be a determinant in one's PsyCap profile since they have been previously linked to some PsyCap dimensions. For instance, age has been found to influence hope-people over 55 years old score lower on hope compared to those under 55 ( Bailey \& Snyder, 2007). Age has also been linked to resilience and it has been found that different elements of resilience tend to emerge in the different ages (González-Arratia Fuentes \& Valdez, 2015). Age has also been connected to optimism, for instance Wong, Gardiner, Lang, \& Coulon, (2008) showed that optimism is higher for older generations (Baby Boomers) compared to younger ones (Generation Y).

Gender has been shown to influence self-efficacy: women tend to perceive themselves as less efficacious then men; and women also show higher levels of resilience compared to men (Busch, 1995; Pajares, 2002; Vaportzis, Clausen, \& Gow, 2017). Educational level has been linked to hope, in that those with a higher education are less likely to experience high levels of hope (Waynor, Gao, \& Dolce, 2012). Tenure and seniority in the organization are linked to self-efficacy and resilience, as explained in the example by Dawkins since more experience contributes to the belief of managing different situations and finding ways to handle difficulties (Bandura, 1993, 1995; Hamill, 2001).

Given these examples, we look at gender, age, educational level, tenure and seniority in the organization and test if they are related to PsyCap profiles or configurations.

Lastly, the usefulness of PsyCap profiles lays in the possibility to check how they relate to outcome variables. The theory behind PsyCap stresses its contribution to performance and financial gain while aligning them with positivity and fulfillment at work, thus allowing for "adequate resource allocation within the realities of today's competitive environment" (Avey, Luthans, \& Youssef-Morgan, 2010, p. 3). Having information about possible PsyCap profiles/types and how they relate to wellbeing or performance would provide knowledge about which elements of PsyCap need to be reinforced in what type of employees in order to boost performance or wellbeing (Dawkins et al., 2015).

Indeed, a significant amount of studies has researched the influence of PsyCap on performance and wellbeing variables (e.g. Larson, 2006; Luthans, Avey, Clapp-Smith, \& Li, 2008; Luthans \& Youssef-Morgan, 2007; Sweetman, Luthans, Avey, \& Luthans, 2011; Youssef-Morgan \& Luthans, 2015). Overall, PsyCap has most commonly been linked to individual performance and job satisfaction (see Luthans \& Youssef-Morgan, 2017).

Various studies have looked at in-role performance as a crucial outcome of PsyCap, showing that higher levels of PsyCap are linked to higher in-role performance (e.g. Du Plessis \& Barkhuizen, 2012; Luthans, Avey, Avolio, \& Peterson, 2010; Luthans, Avey, Clapp-Smith, \& Li, 2008; Peterson, Luthans, Avolio, Walumbwa, \& Zhang, 2011). As for job satisfaction, it has been the most common way to operationalize wellbeing at work as an outcome of PsyCap, and many studies have shown a relationship between PsyCap and job satisfaction (e.g. Abbas, Raja, Darr, \& Bouckenooghe, 2014; Bergheim, Nielsen, Mearns, \& Eid, 2015; Fu, Sun, Wang, Yang, \& Wang, 2013). High levels of PsyCap have also been connected to desirable work attitudes and behaviors because of PsyCap's elements of appreciation and motivation (Meyers, van Woerkom, de Reuver, Bakk, \& Oberski, 2015; Siu, Bakker, \& Jiang, 2014). Particularly, organizational citizenship behavior or OCB has often been associated with PsyCap (e.g. Cameron \& Dutton, 2003; Diener \& Seligman, 2004).

Thus, since in-role performance, job satisfaction and OCB appear to be consistently related by PsyCap, we want to test how these three variables are linked to particular PsyCap profiles or configurations and not only to total PsyCap level. 


\section{Method}

\section{Sample and Procedure}

The sample consists of 1752 employees from 45 Spanish organizations. The companies were approached by members of the research team, explaining the objectives and parameters of the study. Later on, preliminary meetings were organized with management of the companies which agreed to participate where the logistics were specified. Questionnaires were filled out in the workplace of participants, either on paper, tablet or online via a link. Researchers were available for clarifications and confidentiality of the data was guaranteed.

Subjects who had over $30 \%$ missing data were eliminated from the samples. We had less than $5 \%$ missing data in the total database which allows for imputation of data (Schafer, 1999). Therefore, we imputed the missing data using Maximum Likelihood estimation with 25 iterations(Enders, 2001).

$82.4 \%$ of the companies were from the tertiary sector-, and $17.6 \%$ were in the secondary. $52.6 \%$ of the participants were women, $43.8 \%$ were men and $3.5 \%$ did not specify their gender. $27.6 \%$ were younger than 35 years, $55.1 \%$ were between 35 and 55 years old, $15.4 \%$ were over 50 , and $1.9 \%$ did not specify their age. Regarding education, $46.8 \%$ had a university degree, $19.1 \%$ had high school studies, $16.7 \%$ had occupational training, $11.6 \%$ had compulsory education, $1 \%$ had no studies and $4.8 \%$ did not specify their educational level. As for seniority in the organization, $9 \%$ have less than a year, $17.5 \%$ have between 1 and 5 years, $66.1 \%$ have over 5 years and $7.4 \%$ did not specify their seniority. Finally, for job tenure, $15.6 \%$ had less than 1 -year tenure at the same job, $25.9 \%$ had between 1 and 5 years, $51.5 \%$ had over 5 years tenure and $6.9 \%$ did not specify.

\section{Measurement}

Psychological Capital was measured with a modified version of the short Psychological Capital Questionnaire with 12 items (PCQ-12) (Djourova, Rodríguez, Lorente, 2016). The scale measures the four PsyCap dimensions with three items per dimension, based on previously developed and tested scales for self-efficacy(Parker, 1998), hope (Snyder et al., 1996), resilience(Wagnild \& Young, 1993) and optimism (Scheier \& Carver, 1985). Sample items are "I feel confident in representing my work area in meetings with management" (self-efficacy); "I can get through difficult times at work because I've experienced difficulty before "(resilience). The items are evaluated on a Lykert scale from 1 (Completely disagree) to 6 (Completely agree). Reliability for the PsyCap scale was .86, for the self-efficacy subscale .83 , for hope .78 , for resilience .71 and for optimism .83 .

Job satisfaction was measured with 9 items from Cooper, Rout, \& Faragher (1989)'s job satisfaction scale, translated to Spanish by Pérez \& Fidalgo, (1995). Five of the items measure intrinsic job satisfaction and four measure extrinsic job satisfaction. An example of an item for intrinsic job satisfaction is "To what extent do you feel satisfied with the freedom to choose your own method of working?", and an example for extrinsic job satisfaction is "To what extent you feel satisfied with your hours of work?". Subject rate the items on a Lykert scale from 1 (very dissatisfied) to 7 (very satisfied). Cronbach's Alpha was .85 .

In-role performance was measured with 3 items from Williams \& Anderson's scale (1991) on in-role performance. A sample item is "I adequately complete assigned duties". Agreement with the items was rated on a Lykert scale from 1 (strongly agree) to 7 (strongly disagree). Cronbach's Alpha was .77.

OCB was measured with 3 items based on Mackenzie, Podsakoff, \& Podsakoff, (2011). A sample item is "I willingly share expertise, knowledge, and information to help improve the effectiveness of others in my work group". Agreement with the items was rated on a Lykert scale from 1 (strongly agree) to 7 (strongly disagree). Cronbach's Alpha was .67. 


\section{Data Analysis}

We used Latent Profile Analysis (LPA) in Mplus 6. This analysis distributes individuals in latent profiles so as to explain differences in the observed pattern of responses (Geiser, 2013). The analysis is done through testing models with a progressive number of classes to establish the most parsimonious one (with fewest classes) which can explain the data. Belonging to a certain profile is calculated based on probabilities, which makes this technique superior to cluster analysis (Geiser, 2013; Muthén \& Muthén, 2008). Multiple starting values were used to estimate the model in order to avoid convergence on a local solution, as recommended by Peel \& McLachlan, (2000).

To compare between the models with different number of classes we used several criteria: Akaike's information criterion (AIC); Bayesian information criterion (BIC); Lo-Mendell-Rubin Adjusted LRT Test (LMR); Vuong-LoMendell-Rubin Likelihood Ratio Test (VLMR); and Bootstrap Likelihood Ratio Difference test (BLRT) (Nylund, Asparouhov, \& Muthén, 2007). In terms of BIC and AIC indices, the model with lowest values is considered best fitting the data. LMR, VLMR and BLRT provide a $p$-value that if significant, means that the model with $k$ classes is better fitting than a model with k-1 classes (Nylund et al., 2007). A value of Entropy closer to 1 is considered an indicator of clearly delineated classes (Celeux \& Soromenho, 1996).

After the profile analysis, we used a Chi-square test of independence to see if belonging to a certain profile is significantly associated with the demographic variables. We also did as a one-way ANOVA to see if there are significant differences between the profiles on intrinsic job satisfaction, in-role performance and OCB.

\section{Results}

As mentioned, we used latent profile analysis to compare models with two, three, four and five classes. The comparison indices can be seen in Table 1.

Table 1. Model Comparison

\begin{tabular}{llllllll}
\hline & & AIC & BIC & Entropy & LMR & VMLR & BLRT \\
\hline M1 & 2 classes & 15893 & 15997 & 0.85 & 0.00 & 0.00 & 0.00 \\
M2 & 3 classes & 15767 & 15898 & 0.90 & 0.00 & 0.00 & 0.00 \\
M3 & 4 classes & 15660 & 15818 & 0.88 & 0.05 & 0.05 & 0.00 \\
M4 & 5 classes & 15586 & 15772 & 0.86 & 0.29 & 0.28 & 0.00
\end{tabular}

Note: $\mathrm{N}=1752 ; \mathrm{AIC}=$ Akaike's information criterion; $\mathrm{BIC}=$ Bayesian information criterion. VLMRVuong-Lo-Mendell-Rubin Likelihood Ratio Test; LMR- Lo-Mendell- Rubin Adjusted LRT Test; BLRTBootstrap Likelihood Ratio Difference test

$\mathrm{BIC}$ and $\mathrm{AIC}$ indices continue to decrease with each new model with more classes, indicating that fit improves as more classes are tested within the models, and the BLRT p-value supports that. The p-values of the LMR and VMLR demonstrate that the 3 -class solution is better than the 2-class solution; the 4-class solution is better than the 3 -class solution, however the 5 -class model is not a better fit than the 4 -class model. All models have similar values of Entropy (between .85 and .90).

Although BLRT is considered the most robust information criterion, it can be inaccurate in model misspecification or non-normal distributions. Therefore, we considered LMR and VMLR's values as most robust indicators and based on the results, we consider that the 4-class model is most likely to explain our data. This 
solution was chosen also because of parsimony and interpretability of the four profiles that emerged. Graph 1 shows a representation of the 4 profiles according to their mean scores on the four PsyCap dimensions. Table 2 shows the means and standard errors on the four PsyCap dimensions for each of the profiles. Graph 1. Graphical Representation of the 4 latent profiles

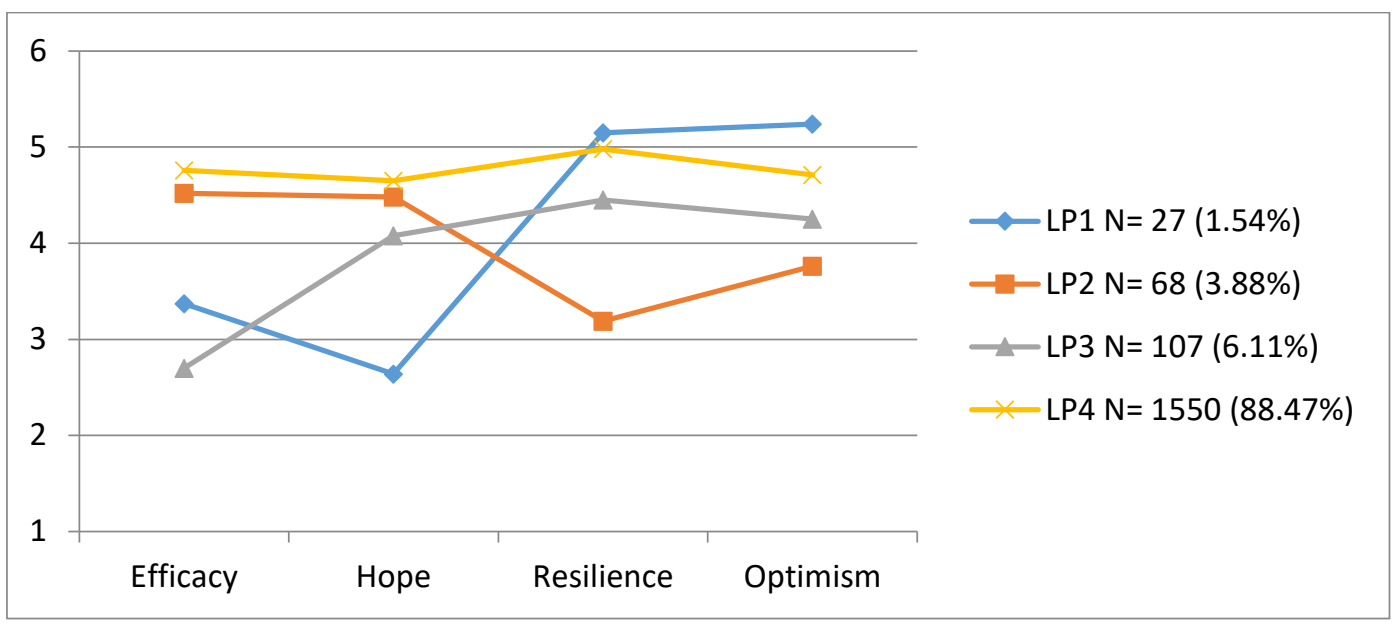

Table 2. Means and standard errors on the four PsyCap dimensions

\begin{tabular}{llllllllll}
\hline & \multicolumn{2}{l}{ Profile 1} & \multicolumn{2}{l}{ Profile 2 } & \multicolumn{2}{l}{ Profile 3 } & \multicolumn{2}{l}{ Profile 4 } \\
& $\mathrm{N}=27$ & \multicolumn{2}{l}{$\mathrm{N}=68$} & \multicolumn{2}{l}{$\mathrm{N}=107$} & \multicolumn{2}{c}{$\mathrm{N}=1550$} \\
& Mean & SE & Mean & SE & Mean & SE & Mean & SE \\
\hline Efficacy & 3.36 & 0.31 & 4.52 & 0.31 & 2.70 & 0.19 & 4.76 & 0.03 \\
Hope & 2.65 & 0.20 & 4.48 & 0.18 & 4.08 & 0.19 & 4.65 & 0.02 \\
Resilience & 5.15 & 0.14 & 3.19 & 0.17 & 4.45 & 0.21 & 4.98 & 0.03 \\
Optimism & 5.24 & 0.24 & 3.76 & 0.23 & 4.25 & 0.20 & 4.71 & 0.03 \\
\hline
\end{tabular}

The analysis revealed that the overwhelming majority of the sample (1550 people) was classified in a profile (Profile 4) with high scores on all four PsyCap dimensions (means between 4.65 and 4.98). The lowest number of individuals, only 27 were classified in Profile 1 which showed lower results on efficacy and hope (3.36 and 2.65) and higher results on resilience and optimism (5.15 and 5.24). 68 people were classified in a mirroring profile, Profile 2, where the levels of efficacy and hope are comparatively higher than the levels of resilience and optimism (respectively 4.52 and 4.48 in comparison to 3.19 and 3.76). Finally, 107 people were classified in Profile 3 with lower results on self-efficacy (2.70) and relatively higher results on hope, resilience and optimism (respectively 4.08, 4.45 and 4.35).

We went on to check the specific demographics of the individuals distributed in each profile and performed a Chi-square test of independence to see if there is a significant association between the demographics and belonging to a certain profile. We also analyzed the standardized residuals and compared them to the critical values that correspond to an alpha of $.05(+/-1.96)$ (MacDonald \& Gardner, 2000). Thus, we were able to see if the observed frequencies of the demographics differ from the expected frequency given the distribution of our data. The Chi square significance, the expected and actuals counts, and the standardized residuals can be seen in Table 3. 
Table 3. Distribution of demographics according to profile

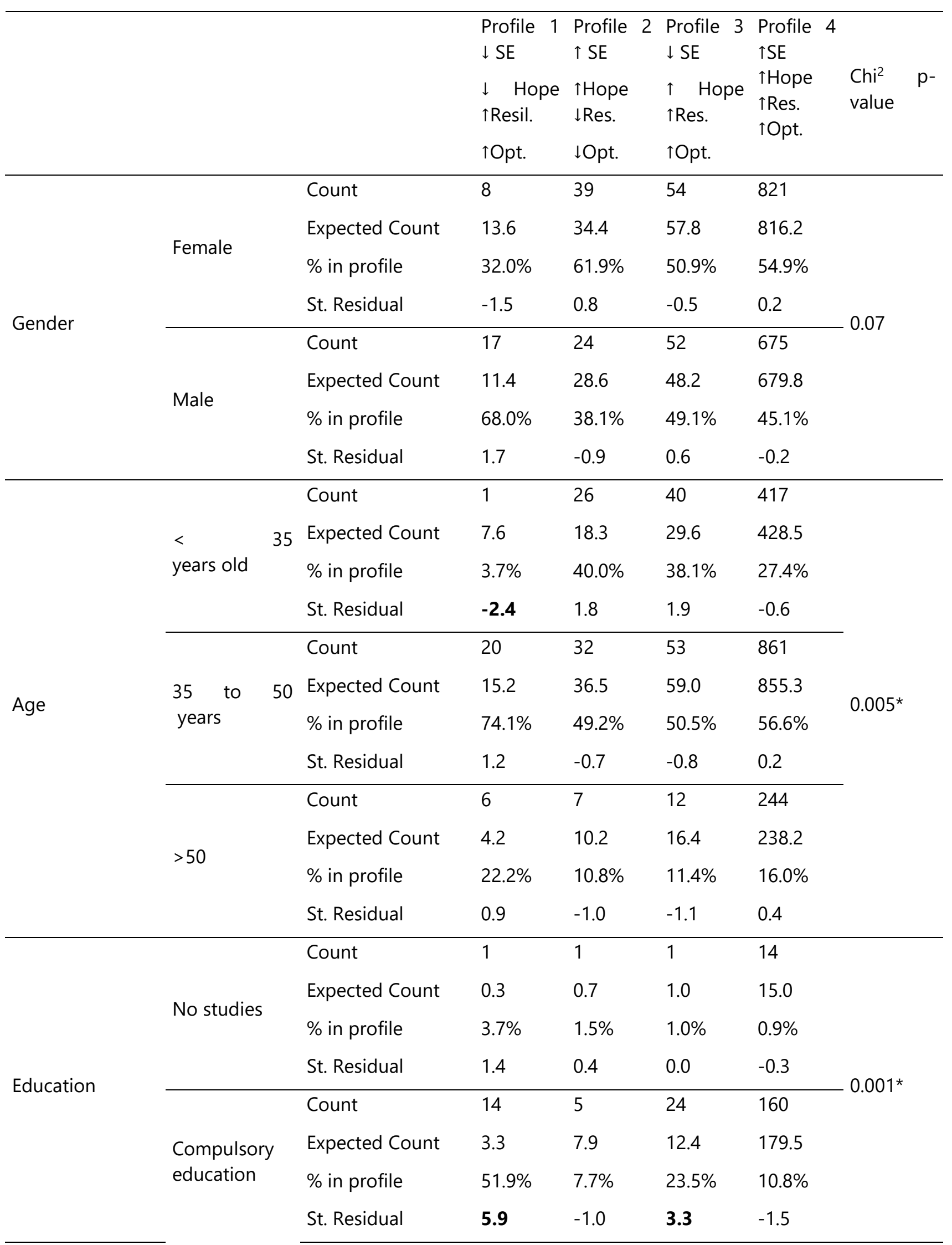




\begin{tabular}{|c|c|c|c|c|c|}
\hline \multirow{5}{*}{$\begin{array}{l}\text { Occupational } \\
\text { training }\end{array}$} & Count & 6 & 12 & 27 & 247 \\
\hline & Expected Count & 4.7 & 11.3 & 17.8 & 258.2 \\
\hline & $\%$ in profile & $22.2 \%$ & $18.5 \%$ & $26.5 \%$ & $16.7 \%$ \\
\hline & Residual & 1.3 & 0.7 & 9.2 & -11.2 \\
\hline & St. Residual & 0.6 & 0.2 & 2.2 & -0.7 \\
\hline \multirow{4}{*}{ High school } & Count & 3 & 11 & 24 & 296 \\
\hline & Expected Count & 5.4 & 13.0 & 20.3 & 295.3 \\
\hline & $\%$ in profile & $11.1 \%$ & $16.9 \%$ & $23.5 \%$ & $20.0 \%$ \\
\hline & St. Residual & -1.0 & -0.5 & 0.8 & 0.0 \\
\hline \multirow{5}{*}{$\begin{array}{l}\text { University } \\
\text { degree }\end{array}$} & Count & 3 & 36 & 26 & 755 \\
\hline & Expected Count & 13.2 & 31.8 & 49.9 & 725.0 \\
\hline & $\%$ in profile & $11.1 \%$ & $55.4 \%$ & $25.5 \%$ & $51.0 \%$ \\
\hline & St. Residual & -2.8 & 0.7 & -3.4 & 1.1 \\
\hline & Count & 0 & 0 & 0 & 9 \\
\hline
\end{tabular}

Others

$\begin{array}{lllll}\text { Expected Count } & 0.1 & 0.3 & 0.5 & 8.0\end{array}$

\begin{tabular}{|c|c|c|c|c|c|c|c|}
\hline & & $\%$ in profile & $0.0 \%$ & $0.0 \%$ & $0.0 \%$ & $0.6 \%$ & \\
\hline & & St. Residual & -0.4 & -0.6 & -0.7 & 0.4 & \\
\hline & & Count & 2.0 & 7.0 & 24.0 & 125.0 & \\
\hline & & Expected Count & 2.4 & 6.2 & 10.0 & 139.3 & \\
\hline & - I year & $\%$ in profile & 0.1 & 0.1 & 0.2 & 0.1 & \\
\hline & & St. Residual & -0.3 & 0.3 & 4.4 & -1.2 & \\
\hline & & Count & 2.0 & 14.0 & 19.0 & 272.0 & \\
\hline Seniority in the & Between & Expected Count & 4.7 & 12.1 & 19.5 & 270.7 & 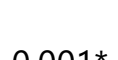 \\
\hline organization & 1 and 5 years & $\%$ in profile & $8.0 \%$ & $21.9 \%$ & $18.4 \%$ & $19.0 \%$ & $0.001^{n}$ \\
\hline & & St. Residual & -1.3 & 0.5 & -0.1 & 0.1 & \\
\hline & & Count & 21.0 & 43.0 & 60.0 & 1034.0 & \\
\hline & & Expected Count & 17.8 & 45.7 & 73.5 & 1021.0 & \\
\hline & $>5$ years & $\%$ in profile & $84.0 \%$ & $67.2 \%$ & $58.3 \%$ & $72.3 \%$ & \\
\hline & & St. Residual & 0.7 & -0.4 & -1.6 & 0.4 & \\
\hline & & Count & 3.0 & 13 & 30 & 228 & \\
\hline & & Expected Count & 4.4 & 10.8 & 16.6 & 242.2 & \\
\hline & & $\%$ in profile & $11.5 \%$ & $20.3 \%$ & $30.3 \%$ & $15.8 \%$ & \\
\hline jod tenure & & St. Residual & -0.7 & 0.7 & 3.3 & -0.9 & $0.0 \angle 0$ \\
\hline & Between & Count & 4.0 & 20 & 23 & 406 & \\
\hline & 1 and 5 years & Expected Count & 7.2 & 17.8 & 27.5 & 400.5 & \\
\hline
\end{tabular}




\begin{tabular}{llllll}
\hline & \% in profile & $15.4 \%$ & $31.3 \%$ & $23.2 \%$ & $28.2 \%$ \\
& St. Residual & -1.2 & 0.5 & -0.9 & 0.3 \\
\hline \multirow{3}{*}{$>5$ years } & Count & 19 & 31 & 46 & 808 \\
& Expected Count & 14.4 & 35.4 & 54.8 & 798.4 \\
& \% in profile & $73.1 \%$ & $48.4 \%$ & $46.5 \%$ & $56.0 \%$ \\
& St. Residual & 1.2 & -0.7 & -1.2 & 0.3
\end{tabular}

According to the Chi-square significance values, age, education, tenure and seniority in the organization are all significantly associated with belonging to a certain profile, while gender was not. However, the results from the standardized residuals showed that in profiles 2 and 4 the demographics were in line with what is expected given the distribution of the overall sample. In profiles 1 and 3 , there were deviations from the expected count on certain demographics.

Specifically, for Profile 1 (low hope and self-efficacy; high resilience and optimism), in terms of age, there were fewer people who were under 35 years old than expected (s. r. $=-2.4<1.96)$. In terms of education, there were more people than expected with a compulsory education (s. r. $=5.9>1.96)$ and fewer people with a university degree (s. r. $=-2.8<1.96)$.

For Profile 3 (low self-efficacy; high hope, resilience and optimism, regarding education, there were more people than expected with a compulsory (s. r. $=3.3>1.96$ ) and an occupational education (s. r. $=2.2>1.96$ ) and fewer people than expected with a university degree (s. r. $=-3.4<1.96)$. Regarding tenure, there were more people than expected with less than a year job tenure (s. r. $=4.4>1.96$ ); the same applies for seniority, there are more people than the expected who have been in the organization less than a year (s. r. $=4.4>1.96$ ).

Thus, people with lower formal education and over 35 years old, were more likely to be classified in Profile 1: low hope and self-efficacy and high resilience and optimism. People with lower formal education and less than a year job tenure and seniority were more likely to be classified in Profile 3, low self-efficacy and high on the other three PsyCap constructs.

Apart from the association of the demographics to the profiles, we also tested if there are significant differences among the latent profiles in the levels of in-role performance, job satisfaction and $O C B$, through an analysis of variance. We tested the assumption for homogeneity of variances using Levine's test which is sensitive to large discrepancies in sample size of groups, as is our case, and the assumption held for intrinsic job satisfaction ( $p=$ $.22)$, for $O C B$ and $(p=.65)$ for in-role performance $(p=.71)$, but not for extrinsic job satisfaction $(p<.05)$. Even though there are robust F-statistics (e.g. Brown-Forsythe test), which can account for the violation of the homogeneity of variances assumption, ANOVA's statistical power can be diminished by the violation and the results may be biased when the discrepancy between samples is very large (Keppel \& Wickens, 2004). Therefore, we decided to only use intrinsic job satisfaction, instead of overall job satisfaction.

Thus, table 4 shows the results from the ANOVA comparison between the four profiles on intrinsic job satisfaction, $O C B$, and in-role performance.

Table 4. One-way ANOVA results for job sat., OCB and in-role performance

\begin{tabular}{|c|c|c|c|}
\hline Profile & Profile & Profile & Profile \\
\hline SE & $\uparrow \mathrm{SE} \uparrow \mathrm{Hope}$ & $\downarrow \mathrm{SE}$ & $\uparrow S E \quad \uparrow$ Hope \\
\hline $\begin{array}{l}\downarrow \quad \text { Hope } \\
\uparrow \text { Res. }\end{array}$ & $\downarrow$ Res. $\downarrow$ Opt. & $\begin{array}{l}\uparrow \quad \text { Hope } \\
\uparrow \text { Res. } \text { TOpt. }\end{array}$ & $\begin{array}{l}\uparrow \text { Res. } \\
\uparrow O p t .\end{array}$ \\
\hline
\end{tabular}


$\uparrow$ Opt.

\begin{tabular}{llllllll}
\hline \multicolumn{5}{l}{ Mean (SD) } & \multicolumn{7}{l}{} & & $\mathrm{df}$ & $\mathrm{F}$ & $\mathrm{\eta} 2$ \\
\hline Intrinsic & 4.19 & 4.86 & 4.78 & 5.26 & 3.00 & $18.06^{* * *}$ & 0.03 \\
satisfaction & $(1.26)$ & $(1.07)$ & $(1.12)$ & $(1.05)$ & & & \\
& 4.74 & 5.15 & 4.63 & 5.54 & & & \\
OCB & $(1.10)$ & $(1.06)$ & $(1.05)$ & $(0.93)$ & 3.00 & $38.64^{* * *}$ & 0.062 \\
& & & & & & & \\
In-role & 6.35 & 6.25 & 6.26 & 6.38 & & & \\
performance & $(0.80)$ & $(.69)$ & $(.67)$ & $(.66)$ & 3.00 & 1.903 & 0.003 \\
& & & & & & & \\
\hline
\end{tabular}

Note. ${ }^{* * *}=p<.001$.

As the ANOVA table indicates, there were significant differences across profiles for intrinsic satisfaction [F ( 3 ; $1748)=18.06, p<.0001]$ and $O C B[F(3 ; 1748)=38.64, p<.0001]$, but not for in-role performance $[F(3 ; 1748)=$ $1.90, p=.127]$.

Tukey's Post Hoc comparison showed that Profile 1 and Profile 2 differ significantly on the mean of intrinsic job satisfaction ( $p<.05)$, thus, individuals with low self-efficacy and hope and high resilience and optimism tend to score lower on intrinsic job satisfaction compared to individuals with high self-efficacy and hope and low resilience and optimism.

There was also a significant difference in the mean of OCB between Profile 2 and Profile 3 meaning that individuals with high self-efficacy and hope and low resilience and optimism tend to score higher on OCB compared to individuals with low self-efficacy and high hope, resilience and optimism.

Profile 4 was significantly different from the other three profiles, showing that those who score high on all four PsyCap dimensions tend to experience higher levels of $O C B$ and intrinsic job satisfaction than people in the other profiles who scored lower on one or more of the components.

\section{Discussion}

The objective of this paper was to verify if individual profiles exist across the four dimensions of PsyCap: selfefficacy, hope, resilience and optimism. A latent profile analysis was carried out where four models were compared and the model with 4-latent profiles was decided to be the best fit to our data. We explored the demographics of the individuals in each profile and discovered that gender had no significant relationship with profile membership, while age, education, seniority in the organization and job tenure did. We also found significant differences between some of the profiles in the way they related to intrinsic satisfaction and OCB.

The overwhelming majority of the sample showed a tendency to score high on all four PsyCap dimensions as illustrated by Profile 4 where $88.47 \%$ of the participants were classified. This result backs up the notion that the four components reinforce one another as indicators of the second-order construct and supports PsyCap as a multidimensional construct, in line with previous literature, which has emphasized the communalities between the four dimensions over the differences (Luthans, Avolio, Avey, et al., 2007; Luthans \& Youssef-Morgan, 2017).

The multidimensional structure of the construct is further validated by the relationship of Profile 4 with the outcomes intrinsic job satisfaction and OCB. People who scored high on all four PsyCap dimensions also had significantly higher scores on OCB and intrinsic job satisfaction, compared to all other profiles. This finding goes 
to show that the combination of all four PsyCap dimensions does in fact relate more strongly to wellbeing and performance outcomes, and it provides evidentiary support for the synergy effect of the four dimensions. Furthermore, it provides evidence in favor of the composite PsyCap score thus responding to Dawkins (2014) 's recommendation to further validate its use.

Although generally speaking, our study endorses the second-order structure of PsyCap, the exploratory Latent Profile Analysis revealed that there are also cases where the scores differ across the four PsyCap dimensions (Profile 1, Profile 2 and Profile 3).

Profile 1 revealed low scores on hope and self-efficacy and higher ones on resilience and optimism. Profile 2 is mirroring Profile 1 with high hope and self-efficacy and lower resilience and optimism. Thus, these two profiles show that there is a specific configuration where people tend to score similarly on optimism and resilience on the one hand, and on self-efficacy and hope on the other. Our results show that there are communalities within these pairs of personal capacities, which are more pronounced for some individuals. We explain further these communalities in the following paragraphs, first for self-efficacy and hope, and then for resilience and optimism.

Out of the four PsyCap dimensions, self-efficacy and hope may have the most theoretical communality, since they are both cognitive sets which refer to expectancies for the future, individual goals and outcomes, and determine behaviour to a large degree (Magaletta \& Oliver, 1999). Overall, both of them are based on a positive attitude towards the probability of achieving goal-related outcomes (Zhou \& Kam, 2016). Moreover, self-efficacy and hope share the common component of agency: agency refers to the motivational energy necessary to pursue a goal and the self-referent beliefs about being able to achieve it (Snyder, 2000). Agency is a component of cognitive nature that enables one to take action in a desired direction and it is the central element that links self-efficacy and hope. The agency component was thus low in profile 1 (low self-efficacy and hope) and high in profile 2 (high self-efficacy and hope).

Given the results we obtained regarding the demographics, agency seems to be linked to age and educational level. People who were classified in the first profile (low self-efficacy and hope) were mostly over 35 years old with a compulsory education, and there were fewer than expected who had a university degree. Individuals with these characteristics are likely to perceive a lack of perspective and fewer goals in terms of career development, due to the socio-economic realities of the labour market that can be an explanation for a diminished agency. For example, there is evidence of an existing tendency on the Spanish labour market that favors the employability of younger workers over older ones (Benito Hernandez \& Ramos Rodrigo, 2009). Also, the sample used in our study was predominantly from the service sector where more and more occupations nowadays require a university degree in order to ascend in position (Weller, 2006). This combination of factors somewhat limits the possibilities for professional development and progressing towards new goals, work positions or titles. This in turn, can inhibit goal-directed behaviour driven by future orientation that is the essence of agency.

The other PsyCap configuration revealed by profiles 1 and 2 is resilience and optimism. The well-known broaden-and-build theory by Fredrickson's (2001) offers some insight as to why these two capacities may go together. The broaden-and-build theory posits that positive emotions broaden people's repertoires of thoughts and actions when facing a difficult or stressful situation, thus leading to more endurance and momentary resilience (Fredrickson et al., 2003). Although POB authors have underlined that self-efficacy, hope and optimism can all serve as pathways to resilience (Luthans, Vogelgesang, \& Lester, 2006), hope and self-efficacy are more based on cognition and thought patterns, while optimism has an emotional component (Peterson, 2000). Thus, in accordance with broaden-and-build theory, optimism is most similar to resilience, as experiencing positive affect relates to a more active approach to difficulties, while negative affect is linked to passive copying and escape or avoidance strategies (Fredrickson, 2001; Fredrickson et al., 2003). Hence, one's level of optimism will also go hand in hand with one's resilience.

Regarding the demographics associated with this pair of capacities, higher resilience and optimism (Profile 1) were significantly associated with an age of over 35 years old. This finding is in line with some previous studies which have shown that older workers may have higher levels of optimism and resilience (Chopik, Kim, \& Smith, 
2015; Peña Vallejo, 2017; Wong et al., 2008). For example, there is evidence that older workers are more resilient and experience less strain and more positivity in the workplace than their younger colleagues who entered the job market later because they possess more social and personal resources accumulated throughout their experience (Rauschenbach \& Hertel, 2011). In addition, younger workers tend to use more passive coping strategies compared to older workers who rely on problem-focused and active emotion-focused coping (Hertel, Rauschenbach, Thielgen, \& Krumm, 2015)(Hertel et al., 2015).

In addition to the mirroring configurations of the PsyCap elements between Profile 1 (low hope and self-efficacy and high resilience and optimism) and Profile 2 (high hope and self-efficacy and low resilience and optimism) there was also a significant difference in the scores on intrinsic job satisfaction between these two profiles. The people classified in Profile 2, high hope and self-efficacy, scored higher on job satisfaction than those in Profile 1 where hope and self-efficacy were lower. This result places emphasis on the agency component, as it shows that even with lower levels of resilience and optimism, those high in hope and self-efficacy (and thus agency) reported more intrinsic job satisfaction than those high on resilience and optimism. Thus, agency appears to be a unique contributor to intrinsic job satisfaction in our sample.

The final pattern that emerged from out data is shown in Profile 3 that had only one component where people would score lower self-efficacy, while the other three PsyCap dimensions were relatively high. In terms of demographics, belonging to this profile was associated with having less formal education, and less than a year tenure and seniority. Having less experience in the workplace is clearly connected to lower levels of self-efficacy since self-efficacy is built through past successes (Bandura, 1995), and thorough the use of pre-existing cognitive skills to manage the current demands (Bandura, 1995). It is likely that employees with less tenure and seniority would feel less confident when dealing with their day-to-day tasks, since self-efficacy requires domain-specific and situation-specific experience. Successful accomplishment of specific tasks is more likely to happen with more time on the same job position or in the same company, so less work experience can be a viable explanation for the lower levels of self-efficacy in Profile 3.

Furthermore, those low on self-efficacy showed significantly lower levels of OCB than people in Profile 2 where self-efficacy and hope were high but resilience and optimism low. Again, this result makes the agency component stand out, since the combination of high self-efficacy and hope contributed more to OCB, compared to the combination of high hope, optimism and resilience.

Thus, our study shows that both in the case of $O C B$ and intrinsic job satisfaction, the combination of high selfefficacy and hope appeared to be contributing to them, even when scores were lower on the other two PsyCap dimensions. Although the optimal configuration for reinforcing positive organizational outcomes is clearly high levels on all PsyCap dimensions, when this is not the case, agency, or having positive future expectancies and goal-directed motivation, is the next most important contributing factor.

\section{Limitations}

The first limitation has to do with the fact that we used a convenience sample and this does not allow us to generalize the results obtained regarding the configurations obtained for Profiles 1,2 and 3. More analysis is needed in different samples to see if similar profiles emerge and if the configurations among the PsyCap components are consistent across other samples. Nevertheless, the demographic characteristics associated to the profiles help to provide reasonable explanations for the existence of the high-low and low-high configurations we obtained.

A second limitation of this work has to do with the statistical analysis used to test if there are differences between the profiles in terms of the outcome variables. Although the use of ANOVA is warranted given that our main objective was to first test for the existence of profiles and then link them to outcome variables, this analysis obliges us to use and treat class membership as an observed variable (Clark \& Muthén, 2009). This can be problematic because Latent Profile Analysis calculates the probability that individuals have to belong to a certain class. This means that there might be some cases of individuals who have much lower probability to belong to 
a certain profile than others, but when class membership is treated as an observed variable both are considered to have a $100 \%$ probability of belonging to that same profile. In other words, the uncertainty of the classification is not accounted for when connecting them to distal outcomes, so it is a narrower way of looking at the relationship between the profiles and the outcomes.

A third limitation has to do with the fact that we were not able to use the overall construct of job satisfaction, but only intrinsic job satisfaction to compare between profiles. However, this was done to ensure the statistical validity of the results from our analysis given the large discrepancies in the numbers of people across profiles.

Future studies that aim to do PsyCap profiling should test both types of job satisfaction, as well as include more outcome variables, such as supervisor-rated performance, turnover intentions, and different types of employee wellbeing to see how different PsyCap profiles relate to them. Such outcomes have been commonly linked to PsyCap and are important for the sustainability of organizations, so relating them to specific profiles would clarify which of the PsyCap dimensions contribute most to a particular outcome.

Furthermore, future works should explore causal relationships between the profiles with the use of longitudinal data. This approach would add great value to PsyCap profiling, especially if databases with more than 2 time points are used, as this allows for more sophisticated analyses, such as Latent Class Growth Modeling and Growth Mixture Modeling (Feingold, Tiberio, \& Capaldi, 2014; Grimm, Castro-Schilo, \& Davoudzadeh, 2013). In addition, we suggest that future studies should explore how PsyCap profiles may evolve over time through diary studies and exploring trajectories, to see in what way they affect organizational outcomes, which is important given the state-like nature of the PsyCap dimensions and the fact that they are not entirely stable over time, and consequently, the profiles they yield may also change over time.

\section{Conclusions}

To conclude, the general tendency revealed in this study is high scores across all four PsyCap components, which is in support of the unitary structure of PsyCap where its four dimensions converge into an underlying positive capacity and motivation. Yet, the existence of the smaller profiles is in line with Rego et al., (2010)' s proposal that future research should study simultaneously the effects of PsyCap as a second-order factor and the effects of each dimension separately, in order to obtain more detailed knowledge of how each component contributes (or not) to desirable outcomes.

There is also a need to replicate the profile analysis in different samples, including in ones that contain data from the primary sector, in order to check if the same profiles emerge, or there are other configurations for different samples or contexts. If a consistent tendency is discovered for profile emergence, it would be informative to use the individual PsyCap profiles as predictors of organizational outcomes, rather than the composite PsyCap score that tends to omit at least some information. That being said, in studies where PsyCap is not a central variable, the use of the composite PsyCap score is justified by a tendency for scoring in a similar way on all four dimensions.

\section{Bibliography:}

1. Abbas, M., Raja, U., Darr, W., \& Bouckenooghe, D. (2014). Combined Effects of Perceived Politics and Psychological Capital on Job Satisfaction, Turnover Intentions, and Performance. Journal of Management , 40(7), 1813-1830. https://doi.org/10.1177/0149206312455243

2. Avey, J. B., Luthans, F., \& Youssef-Morgan, C. (2010). The Additive Value of Positive Psychological Capital in Predicting Work Attitudes and Behaviors. Journal of Management, 36(2), 430-452. https://doi.org/10.1177/0149206308329961

3. Avey, J. B., Reichard, R., Luthans, F., \& Mhatre, K. H. (2011). Meta-analysis of the impact of positive psychological capital on employee attitudes, behaviors, and performance. Human Resource Development 
Quarterly, 22(2), 127-152. https://doi.org/10.1002/hrdq.20070

4. Bagozzi, R. P., \& Edwards, J. R. (1998). A General Apporach for Representing Constructs in Oganizational Research. Organizational Research Methods. Retrieved from https://deepblue.lib.umich.edu/bitstream/handle/2027.42/68713/10.1177_109442819800100104.pdf?sequ ence $=$ 2\&isAllowed $=\mathrm{y}$

5. Bailey, T. C., \& Snyder, C. R. (2007). Satisfaction with life and hope: A look at age and marital status. Psychological Record, 57(2), 233-240. https://doi.org/10.1007/BF03395574

6. Bandura, A. (1993). Perceived Self-Efficacy-in-Cognitive-Development-and-Functioning. Educational Psychologist, 28(2), 117-148. $\quad$ Retrieved from http://homepages.se.edu/cvonbergen/files/2013/01/Perceived-Self-Efficacy-in-Cognitive-Developmentand-Functioning.pdf

7. Bandura, A. (1995). Self-efficacy in changing societies. Cambridge university press.

8. Bass, B. M. (1999). Two Decades of Research and Development in Transformational Leadership. European Journal of Work and Organizational Psychology, 8(1), 9-32. https://doi.org/10.1080/135943299398410

9. Benito Hernandez, S., \& Ramos Rodrigo, J. (2009). La creación de puestos de trabajo para el desarrollo profesional de las personas mayores de cuarenta años: el microemprendimiento. REVESCO. Revista de Estudios Cooperativos, (98). Retrieved from http://www.cis.es/cis/opencm/ES/1_encuestas/estudios/ver.jsp?estudio=2542\&cuestionario=2569\&muestr $\mathrm{a}=800$

10. Bergheim, K., Nielsen, M. B., Mearns, K., \& Eid, J. (2015). The relationship between psychological capital, job satisfaction, and safety perceptions in the maritime industry. Safety Science, 74, 27-36. https://doi.org/10.1016/j.ssci.2014.11.024

11. Busch, T. (1995). Gender Differences in Self-Efficacy and Attitudes toward Computers. Journal of Educational Computing Research, 12(2), 147-158. https://doi.org/10.2190/H7E1-XMM7-GU9B-3HWR

12. Cameron, K., \& Dutton, J. (Eds. ). (2003). Positive organizational scholarship: Foundations of a new discipline.

13. Carifio, J., \& Rhodes, L. (2002). Construct validities and the empirical relationships between optimism, hope, self-efficacy, and locus of control. Work, 19, 125-136. https://doi.org/10.1037/0022-3514.51.6.1257

14. Celeux, G., \& Soromenho, G. (1996). An entropy criterion for assessing the number of clusters in a mixture model. Journal of Classification, 13(2)(195-212).

15. Chopik, W. J., Kim, E. S., \& Smith, J. (2015). Changes in Optimism Are Associated With Changes in Health Over Time Among Older Adults. Social Psychological and Personality Science, 6(7), 814-822. https://doi.org/10.1177/1948550615590199

16. Clark, S., \& Muthén, B. O. (2009). Relating Latent Class Analysis Results to Variables not Included in the Analysis. Statisticallnnovations.com, 1-55. Retrieved from http://statmodel2.com/download/relatinglca.pdf

17. Dawkins, S. (2014). New directions in Psychological Capital research: A critical analysis and theoretical and empirical extensions to individual- and team- level measurement, (March), 1-297.

18. Dawkins, S., Martin, A., Scott, J., \& Sanderson, K. (2013). Building on the positives: A psychometric review and critical analysis of the construct of Psychological Capital. Journal of Occupational and Organizational 
Psychology, 86(3), 348-370. https://doi.org/10.1111/joop.12007

19. Dawkins, S., Martin, A., Scott, J., \& Sanderson, K. (2015). Advancing conceptualization and measurement of psychological capital as a collective construct. Human Relations, 68(6), 925-949. https://doi.org/10.1177/0018726714549645

20. Diener, E., \& Seligman, M. E. (2004). Beyond money: Toward an economy of well-being. Psychological Science in the Public Interest, 5(1)(1-31).

21. Du Plessis, Y., \& Barkhuizen, N. (2012). Psychological Capital, a Requisite for Organisational Performance in South Africa. South African Journal of Economic and Management Sciences. https://doi.org/10.4102/SAJEMS.V15I1.122

22. Edwards, J. R. (2001). Multidimensional constructs in O organizational behavior research: An integrative analytical framework. Organizational Research Methods, 4(2), 144-192. https://doi.org/10.1177/109442810142004

23. Enders, C. K. (2001). A Primer on maximum likelihood algorithms available for use with missing data. Structural Equation Modeling, 8(1), 128-141. https://doi.org/10.1207/S15328007SEM0801_7

24. Feingold, A., Tiberio, S. S., \& Capaldi, D. M. (2014). New approaches for examining associations with latent categorical variables: Applications to substance abuse and aggression. Psychology of Addictive Behaviors, 28(1), 257-267. https://doi.org/10.1037/a0031487

25. Fredrickson, B. L. (2001). The role of positive emotions in positive psychology. The broaden-and-build theory of positive emotions. The American Psychologist, 56(3), 218-26. https://doi.org/10.1037/0003-066X.56.3.218

26. Fredrickson, B. L., Tugade, M. M., Waugh, C. E., \& Larkin, G. R. (2003). What good are positive emotions in crises? A prospective study of resilience and emotions following the terrorist attacks on the United States on September 11th, 2001. Journal of Personality and Social Psychology, 84(2), 365-76. https://doi.org/10.1037/0022-3514.84.2.365

27. Fu, J., Sun, W., Wang, Y., Yang, X., \& Wang, L. (2013). Improving job satisfaction of Chinese doctors: The positive effects of perceived organizational support and psychological capital. Public Health, 127(10), 946951. https://doi.org/10.1016/j.puhe.2012.12.017

28. González-Arratia Fuentes, N. I., \& Valdez, J. L. (2015). Resiliencia. Diferencias por Edad en Hombres y Mujeres Mexicanos. Acta de Investigación Psicológica, 5(2), 1996-2010. https://doi.org/10.1016/S20074719(15)30019-3

29. Grimm, K. J., Castro-Schilo, L., \& Davoudzadeh, P. (2013). Modeling Intraindividual Change in Nonlinear Growth Models with Latent Change Scores. GeroPsych: The Journal of Gerontopsychology and Geriatric Psychiatry, 26(3), 153-162. https://doi.org/10.1024/1662-9647/a000093

30. Hamill, S. K. (2001). Resilience and Self-Efficacy: the Importance of Efficacy Beliefs and Coping Mechanisms in Resilient Adolescents, (July), 115-146.

31. Hertel, G., Rauschenbach, C., Thielgen, M. M., \& Krumm, S. (2015). Are older workers more active copers? Longitudinal effects of age-contingent coping on strain at work. Journal of Organizational Behavior, 36(4), 514-537. https://doi.org/10.1002/job.1995

32. Imam, T., Ali, H., \& Soo, H. S. (2017). Psychological Capital: A Comprehensive Review and Classification. Asian Journalo Of Multidisciplinary Studies, 5(10), 152-162. 
33. Judge, T. A., \& Bono, J. E. (2001). Relationship of Core Self-Evaluations Traits-Self-Esteem, Generalized SelfEfficacy, Locus of Control, and Emotional Stability-With Job Satisfaction and Job Performance: A MetaAnalysis. Journal of Applied Psychology, 86(1), 80-92. https://doi.org/10.1037//0021-9010.86.1.80

34. Kauko-Valli, S. A., \& Haapanen, M. (2013). Positive psychological capital and growth intentions of entrepreneurs. Academy of Management Proceedings.Briarcliff Manor, NY 10510: Academy of Management, $1,13473$.

35. Keppel, G., \& Wickens, T. D. (2004). Effect Size, Power, and Sample Size. In Design and Analysis (Vol. 2, pp. 1-10). Retrieved from http://www.skidmore.edu/ hfoley/Handouts/K.Ch8.notes.pdf

36. Larson, M. (2006). Potential Added Value of Psychological Capital in Predicting Work Attitudes. Journal of Leadership and Organizational Studies (Vol. 13). Retrieved from http://journals.sagepub.com/doi/pdf/10.1177/10717919070130010701

37. Luthans, F., Avey, J. B., Avolio, B., \& Peterson, S. J. (2010). The development and resulting performance impact of positive psychological capital. Human Resource Development Quarterly, 21(1), 41-67. https://doi.org/10.1002/hrdq.20034

38. Luthans, F., Avey, J. B., Clapp-Smith, R., \& Li, W. (2008). More evidence on the value of Chinese workers' psychological capital: A potentially unlimited competitive resource? The International Journal of Human Resource Management, 19(5), 818-827. https://doi.org/10.1080/09585190801991194

39. Luthans, F., Avolio, B., \& Avey, J. (2007). Positive psychological capital: Measurement and relationship with performance and satisfaction. Personnel Psychology, 60(3), 541-572. https://doi.org/10.1111/j.17446570.2007.00083.x

40. Luthans, F., Avolio, B., Avey, J. B., \& Norman, S. M. (2007). Positive psychological capital: Measurement and relationship with performance and satisfaction. Personnel Psychology, 60(3), 541-572. https://doi.org/10.1111/j.1744-6570.2007.00083.x

41. Luthans, F., \& Jensen, S. M. (2002a). Hope: A New Positive Strength for Human Resource Development. Human Resource Development Review, 1(3), 304-322. https://doi.org/10.1177/1534484302013003

42. Luthans, F., \& Jensen, S. M. (2002b). Hope: A new positive strengths for human resource development. Human Resource Development Review, 3(3), 304-322. Retrieved from http://www.bus.umich.edu/

43. Luthans, F., Vogelgesang, G. R., \& Lester, P. B. (2006). Developing the Psychological Capital of Resiliency. Human Resource Development Review, 5(1), 25-44. https://doi.org/10.1177/1534484305285335

44. Luthans, F., \& Youssef-Morgan, C. (2007). Emerging positive organizational behavior. Journal of Management. Carr Compton Keyes \& Haidt Lopez \& Snyder Snyder \& Lopez. https://doi.org/10.1177/0149206307300814

45. Luthans, F., \& Youssef-Morgan, C. (2017). Psychological Capital: An Evidence-Based Positive Approach. Annual Review of Organizational Psychology and Organizational Behavior, 4(January), 1-28. https://doi.org/10.1146/annurev-orgpsych-032516-113324

46. MacDonald, P. L., \& Gardner, R. C. (2000). Type I error rate comparisons of post hoc procedures for I $\times$ J chisquare tables. Educational and Psychological Measurement, 60(5), 735-754. https://doi.org/10.1177/00131640021970871

47. Mackenzie, S. B., Podsakoff, P. M., \& Podsakoff, N. P. (2011). Construct Measurement and Validation P 
Rocedures in Mis and B Ehavioral Research: Integrating New and Existing Techniques. MIS Quarterly, 35(2), 293-334. https://doi.org/10.2307/23044045

48. Magaletta, P. R., \& Oliver, J. M. (1999). The hope construct, will, and ways: Their relations with self-efficacy, optimism, and general well-being. Journal of Clinical Psychology, 55(5), 539-551. https://doi.org/10.1002/(SICI)1097-4679(199905)55:5<539::AID-JCLP2>3.0.CO;2-G

49. Meyers, M. C., van Woerkom, M., de Reuver, R. S. M., Bakk, Z., \& Oberski, D. L. (2015). Enhancing Psychological Capital and Personal Growth Initiative: Working on Strengths or Deficiencies. Journal of Counseling Psychology, 62(1), 50-62. https://doi.org/10.1037/cou0000050

50. Newman, A., Ucbasaran, D., Zhu, F., \& Hirst, G. (2014). Psychological capital: A review and synthesis. Journal of Organizational Behavior, 35(SUPPL.1), S120-S138. https://doi.org/10.1002/job.1916

51. Nylund, K. L., Asparouhov, T., \& Muthén, B. O. (2007). Deciding on the number of classes in latent class analysis and growth mixture modeling: A Monte Carlo simulation study. Structural Equation Modeling, 14(4), 535-569. https://doi.org/10.1080/10705510701575396

52. Pajares, F. (2002). Gender and perceived self-efficacy in self-regulated learning. Theory into Practice, $41(2)$, 116-125. https://doi.org/10.1207/s15430421tip4102_8

53. Parker, S. K. (1998). Enhancing role breadth self-efficacy: the roles of job enrichment and other organizational interventions. The Journal of Applied Psychology, 83(6), 835-52. Retrieved from http://www.ncbi.nlm.nih.gov/pubmed/9885197

54. Peel, D., \& McLachlan, G. J. (2000). Robust mixture modelling using the t distribution. Statistics and Computing, 10(4)(339-348).

55. Peña Vallejo, A. (2017). La generación $Y$ ante el desafío de su inserción laboral: realidades frente a estereotipos; Generation $Y$ facing the challenge of employability: facts against stereotypes. ARBOR Ciencia, Pensamiento Y Cultura, 193783(375), 210-1963. https://doi.org/10.3989/arbor.2017.783n1006

56. Pérez, J., \& Fidalgo, M. (1995). NTP 394: Satisfacción laboral: escala general de satisfacción. Madrid: Instituto Nacional de Seguridad E Higiene En.

57. Peterson, C. (2000). The future of optimism. American Psychologist, 55(1), 44-55. https://doi.org/10.1037/0003-066X.55.1.44

58. Peterson, S. J., Luthans, F., Avolio, B., Walumbwa, Z., \& Zhang, F. O. (2011). Psychological capital and employee performance: A latent growth modeling approach. Personnel Psychology, 64, 427-450. https://doi.org/10.1111/j.1744-6570.2003.tb00246.x

59. Rauschenbach, C., \& Hertel, G. (2011). Age differences in strain and emotional reactivity to stressors in professional careers. Stress and Health, 27(2)(48-60).

60. Rego, A., Marques, C., Leal, S., Sousa, F., \& Pina e Cunha, M. (2010). Psychological capital and performance of Portuguese civil servants: exploring neutralizers in the context of an appraisal system. The International Journal of Human Resource Management, 21(9), 1531-1552. https://doi.org/10.1080/09585192.2010.488459

61. Schafer, J. L. (1999). Statistical Methods in Medical Research. Stat Methods Med Res, 8(1), 3-15. https://doi.org/10.1177/096228029900800102

62. Scheier, M. F., \& Carver, C. S. (1985). Optimism, coping, and health: assessment and implications of 
generalized outcome expectancies. Health Psychol, 4(3), 219-47. https://doi.org/10.1037/0278-6133.4.3.219

63. Siu, O. L., Bakker, A. B., \& Jiang, X. (2014). Psychological Capital Among University Students: Relationships with Study Engagement and Intrinsic Motivation. Journal of Happiness Studies, 15(4), 979-994. https://doi.org/10.1007/s10902-013-9459-2

64. Snyder, C. R., Sympson, S. C., Ybasco, F. C., Borders, T. F., Babyak, M. a, \& Higgins, R. L. (1996). Development and validation of the State Hope Scale. Journal of Personality and Social Psychology, 70(2), 321-335. https://doi.org/10.1037/0022-3514.70.2.321

65. Sweetman, D. S., Luthans, F., Avey, J. B., \& Luthans, B. C. (2011). Relationship between positive psychological capital and creative performance. Canadian Journal of Administrative Sciences / Revue Canadienne Des Sciences de l'Administration, 28(1), 4-13. https://doi.org/10.1002/cjas.175

66. Vaportzis, E., Clausen, M. G., \& Gow, A. J. (2017). Older Adults Perceptions of Technology and Barriers to Interacting with Tablet Computers: A Focus Group Study. Frontiers in Psychology, 8, 1687. https://doi.org/10.3389/fpsyg.2017.01687

67. Wagnild, G., \& Young, H. (1993). Development and psychometric evaluation of the resiliency scale. Journal of Nursing Measurement, 1(2), 165-178.

68. Waynor, W. R., Gao, N., \& Dolce, J. N. (2012). The Paradoxical Relationship Between Hope and the Educational Level of People in Recovery. American Journal of Psychiatric Rehabilitation, 15(3), 299-311. https://doi.org/10.1080/15487768.2012.703560

69. Weller, J. (2006). Procesos de exclusión e inclusión laboral. Naciones Unidas, (August), 1-83. Retrieved from http://repository.eclac.org/bitstream/handle/11362/5449/S01121044_es.pdf?sequence=1\&isAllowed=y

70. Williams, L. J., \& Anderson, S. E. (1991). Job Satisfaction and Organizational Commitment as Predictors of Organizational Citizenship and In-Role Behaviors. Journal of Management, 17(3), 601-617. https://doi.org/10.1177/014920639101700305

71. Wong, M., Gardiner, E., Lang, W., \& Coulon, L. (2008). Generational differences in personality and motivation: Do they exist and what are the implications for the workplace? Journal of Managerial Psychology, 23(8), 878890. https://doi.org/10.1108/02683940810904376

72. Youssef-Morgan, C. M., \& Luthans, F. (2015). Psychological capital and well-being. Stress and Health, 31(3), 180-188.

73. Zhou, M., \& Kam, C. C. S. (2016). Hope and General Self-efficacy: Two Measures of the Same Construct? Journal of Psychology: Interdisciplinary and Applied, 150(5), 543-559. https://doi.org/10.1080/00223980.2015.1113495 